\title{
Elsinore: un cuaderno de escritura
}

Fernando Salazar Torres

Universidad Autónoma Metropolitana-Iztapalapa

\section{Resumen}

La idea general del artículo propone el relato Elsinore: un cuaderno como una novela de formación, cuyos rasgos estéticos permiten notar el aspecto biográfico del autor en el proceso de formación que va tomando el protagonista. La notable relación que conquista Elizondo entre escritura, memoria y sueńo, junto a la hibridez que constituye, permiten analizar a la narración como la textualidad onírica del autor, la cual es el relato mismo; es decir, la escritura que se presenta como una obra acabada, que es un pasado, traído a la actualidad mediante la memoria, es sueño.

Palabras clave: Elizondo, escritura, proceso de formación, cuaderno y memoria.

\section{Abstract}

The general idea of the article proposes the Elsinore story: a notebook as a novel of formation, whose esthetic features allow to show the biographical aspect of the author in the training process that is taking the protagonist. The remarkable relationship that conquers Elizondo between writing, memory and dream, with the hybridity that constitute, allow analyze in the narration as dreamlike textuality of the author, which is the same story, that is, the writing that occurs as a finished work, is a past, brought to the present through memory, is dream.

Keywords: Elizondo, writing, training process, notebook and memory. 
Escribo. Escribo que escribo. Mentalmente me veo escribir que escribo y también puedo verme ver que escribo. Me recuerdo escribiendo ya y también viéndome que escribia.

SALVAdor Elizondo

\section{Introducción}

Salvador Elizondo Alcalde (Ciudad de México, 19 de diciembre Sde 1932-30 de marzo de 2006), escritor, traductor y crítico literario. Desarrolló un estilo literario cosmopolita, al margen de las corrientes realistas y nacionalistas que imperaban en la época, con importantes influencias de autores como Stéphane Mallarmé, James Joyce, Ezra Pound, George Bataille y Jorge Luis Borges.

Forma parte de la Generación de Medio Siglo, constituida por Juan García Ponce, Inés Arredondo, Sergio Pitol, José de la Colina, Juan José Gurrola, Jorge Ibargüengoitia, Juan Vicente Melo, entre otros. Estos autores modificaron la expresión de la literatura hispanoamericana - novela, poesía, crítica y teatro-; transformaron el modelo hegemónico literario, vinculado al referente nacionalista, a motivos políticos, históricos y sociales, por su interés renovador en la forma, reivindicación de temas y tonos. Realizaron una lectura crítica de la tradición universal y una concepción distinta de la función del arte y del artista. El trabajo del grupo de Elizondo se refirió, parcialmente, a la realidad mexicana.

En las obras de esta generación se comprende el esmero por la experimentación y la preocupación por temas poco frecuentados en ese momento por la literatura mexicana, como el erotismo, la difusa frontera entre sueńo y vigilia, la escritura, el cosmopolitismo, la exploración del mal, la metaficción e intertextualidad y el arte impulsado por el ejemplo de Octavio Paz y Jaime García Terrés. 
Elizondo es autor de Poemas, 1960; Luchino Visconti, 1963; Farabeuf o la crónica de un instante, 1965; Narda o el verano, 1966; Autobiografía, 1966; El hipogeo secreto, 1968; Cuaderno de escritura, 1969; El retrato de Zoe, 1969; El grafógrafo,_1972; Contextos, 1973; Museo poético, 1974; Antología personal, 1974; Miscast, 1981; Camera lucida, 1983; La luz que regresa, 1984; Elsinore: un cuaderno, 1988; Estanquillo, 1992; Teoría del infierno, 1993; Autobiografía precoz, 2000; Pasado anterior, 2007 y Mar de Iguanas, 2010.

Además, participó en la revista $S N O B$, de la cual fue director, junto con García Ponce y Emilio García Riera. Esta publicación funcionó, a pesar de su corta vida, como una estancia en la que experimentaron con el lenguaje y la escritura de textos heterodoxos. $S N O B$ agrupó el pensamiento de la generación, interesada en romper con los límites de lo real y lo ficticio.

\section{Estado de la cuestión}

La narrativa de Elizondo presenta un mundo poético. De éste pueden mencionarse Farabeuf o la crónica de un instante y El hipogeo secreto. Otras de tal índole, pero cuyo relato es más breve, son Narda o el verano, El retrato de Zoe y otras mentiras, El grafógrafo, Camera lucida y Elsinore: un cuaderno. Las obras mencionadas son, en general, las más estudiadas por los críticos, y aunque la literatura de Elizondo se ha analizado suficientemente, el relato en cuestión carece de una reflexión amplia. La mayoría de los estudios se ocupan de Farabeuf o El Hipogeo secreto. Sobre Elsinore: un cuaderno se han localizado comentarios y breves análisis en artículos y libros. Manuel Durán (1973), en Tríptico mexicano, serie de ensayos dedicados a Elizondo, Juan Rulfo y Carlos Fuentes, observa los orígenes de Farabeuf. Incluso, menciona que la obra de Elizondo ofrece una forma lúcida del mundo irreal e irracional, asimismo considera lecturas implícitas en gran parte de su trabajo creativo. 
Por ejemplo, los temas del erotismo, amor, sexualidad, suplicio, tiempo y muerte, presentes en el libro recién mencionado, son parte fundamental de las lecturas que efectúo de George Bataille.

Otra de las constantes de Elizondo son el tema del espejo y el desdoblamiento de la conciencia y del personaje en la novela. Ello provoca una irrupción en la diégesis, que hace que el tiempo de la novela no corresponda al del calendario ni al de los hombres que fechan los sucesos. Cierta falta de identidad, ilusión, y recuerdo de sí mismo ocasiona una vacilante seguridad del tiempo y, por tanto, de nosotros mismos.

Norma Angélica Cuevas Velasco (2006) vincula los aportes del espacio literario de Maurice Blanchot como teoría en la literatura, en tanto que espacio poético, cuya herramienta crítica aplica al estudio de la novela El hipogeo secreto. Primero lleva a cabo un examen teórico sobre la literatura como espacio, después sobre los objetivos de la nouveau roman y la descripción como generador de espacios en los textos narrativos. Incluso, estudia al espacio literario y poético a nivel metatextual. Finalmente, mediante la teoría deconstruccionista analiza el espacio poético en El hipogeo secreto.

Javier García-Galiano (2006) expresa sobre Elsinore que "el título es ya una invocación, procede de un recuerdo que, sin embargo, no se evoca ni deviene en $[s i c]$ una iniciación, sino que se convierte en un relato admirable en el que la obsesión que siempre animó la obra de Elizondo - la escritura misma - adquiere formas aparentemente más tradicionales, lo cual puede facilitar su lectura" (2006: 18-19). ${ }^{1}$

Dermot F. Curley (2008) toma en cuenta, exclusivamente, los cinco títulos arriba mencionados para proponer una investigación sobre la presencia del sueńo, el tiempo, el lenguaje, la escritura, los recursos de técnicas de otras disciplinas, tales como la fotografía y la pintura, en la narrativa de Elizondo. A diferencia de los análisis

\footnotetext{
${ }^{1}$ Las cursivas son mías.
} 
anteriores, éste contiene un breve comentario dedicado a Elsinore, en el que dice que "representa [...] uno de los pocos escritos biográficos del autor, el cual rompe [...] con una escritura solipsista" (2008: 313). Esclarecer qué significa romper con la escritura solipsista es uno de los propósitos de este trabajo. Curley menciona que tal libro es resultado de varios cuadernos y representa la transcripción a la literatura del relato (321-322).

Daniel Sada (2009) dice que Elsinore, en opinión de especialistas, "se convirtió en un clásico de la literatura mexicana [...] acaso porque el autor abre su prosa a coloquialismos en consonancia con sus constantes de antaño". El autor da cuenta de que la narrativa de Elizondo, gracias a la importancia del sueño y la imaginación en la escritura, es una manera de ver la realidad y de narrarla, como es el caso del sueño en Elsinore. Su escritura es sueño, memoria, cuaderno que se agota.

Los propósitos de este trabajo consisten en registrar si Elsinore: un cuaderno tiene caracteres de formación y explicar cómo suceden, así como explicar sus alcances; revisar y analizar los contenidos temáticos en la narración: la escritura, la teoría de espejos y el concepto de montaje, como partes integrales de la estética de Elizondo.

\section{La escritura: evocación y memoria}

Elsinore: un cuaderno es el relato de un sueño que contiene sucesos reales ficcionalizados, cuando Elizondo estudió tres años en una escuela militar de California. Este doble carácter es lo que Paul Ricouer llama ficcionalización de la historia e historicización de la ficción. La obra en cuestión presenta tal entrecruzamiento. Está dividida en cinco secciones. Es la historia de Sal y de su amigo Fred, internados en Elsinore Naval and Military School de California, mejor conocida en la memoria de Sal por sus siglas ENMS. 
Son hechos que ocurren meses después de terminada la II Guerra Mundial, con trasfondos de propaganda de guerra, películas del momento — The Outlaw (1943) y Gilda (1946)—, y la situación marginal de inmigrantes mexicanos. Sal y Fred escapan de la base militar — acto jamás ocurrido en la escuela — y el relato narra los acontecimientos de esa aventura, así como los años de adolescencia de Elizondo. Ambos escapan en el bote Jenny una noche antes del día de Acción de Gracias, y en ese mismo momento, después que Sal le regaló una botella de whisky a Yuca y a Diosdado, éstos riñen con armas blancas, lo que provoca el asesinato del primero a manos del segundo. El protagonista tiene encuentros con su tía, se enamora de Mrs. Simpson, lo ascienden dos veces en la escuela militar. Al regresar a la escuela, sin que la base militar se haya dado cuenta de la ausencia de los dos amigos, descubren el asesinato de Yuca, y se celebra el $15^{\circ}$ cumpleaños de Sal. Por otra parte, la amistad de ambos, Sal y Fred, se deteriora.

Todo el relato es soñado en un presente por el autor; sin embargo, no sólo se trata del sueño de ahora, sino que en la escritura suceden sueños al mismo tiempo que ella se manifiesta a sí misma. La idea de escritura puede comprenderse como el proceso creativo de composición, tal y como ocurre con El libro vacio, de Josefina Vicens, cuyo protagonista planea escribir un libro, y para ello realiza la corrección, acomodo y reescritura en un borrador que intenta transcribir en otro libro que permanece vacío. Otro concepto de escritura es sugerido por Roland Barthes (2009), quien explica que el grado cero de la escritura es un no-estilo o modo oral de la escritura. Su modo indicativo se libera de la contención con respecto al orden marcado por el lenguaje. Aspira a una neutralidad en la cual se eliminan los caracteres sociales del lenguaje, la forma neutral de la escritura es su grado cero, su ausencia de los vínculos con aspectos sociales, políticos y económicos. Jacques Derrida (1989) también sugiere un concepto de escritura, definida por ser signifi- 
cante del significante y por ser el movimiento del lenguaje, aunque es falsificable porque no supone nuestra presencia, sino nuestra ausencia. La escritura no requiere de la voz, phoné, para develar su verdad. Derrida sostiene que la tradición le ha dado a la escritura el lugar para designar la palabra.

Todas estas ideas de la escritura son conocidas por Elizondo; no obstante, él posee y desarrolla en algunos libros su examen e ideas sobre la escritura. Por ejemplo, el texto El grafógrafo, cuyo título es homónimo al del libro, plantea un desorden, simula una múltiple funcionalidad de la escritura que va desde la metatextual hasta ser recuerdo, mirada y sueño en distintos planos. La escritura es la posibilidad de la imaginación que rompe con los horizontes temporales y espaciales. El caso de Elsinore sorprende, pues su estructura y división en apartados insinúan ser cinco grandes oraciones, lo que las hace acercarse a la palabra hablada, a la oración, la voz, la conversación de alguien que cuenta una historia. Pese a ello, el narrador dice que se trata de un sueño en tiempo presente. Está soñando que escribe y ésta actividad necesita de un espacio en el cual manifestarse: un cuaderno. Este es el lugar más inmediato donde se encuentra; no obstante, si se trata de soñar que se escribe, entonces el espacio es la memoria o bien, propiamente, el sueño. Conforme se desarrolla la escritura, se manifiestan sueños. Elsinore es escritura, sueño, memoria, cuaderno que se agota.

Una leyenda paradisiaca penetraría la imaginación y el sueño, se prolongaría a lo largo de los meses y los años en otro sueño y éste a su vez se mezclaría con otros y así sucesivamente hasta que la vida entera quedaba rodeada de sueńos, aprisionando en su centro un sueño único que ahora que lo estoy soñando otra vez por escrito los abarca a todos y en el que todos se confunden en una sola imagen: la del Deseo. (Elizondo, 2001: 15-16) 
El relato presenta rasgos autobiográficos simulados por Sal. Éste es nombre cortado de Salvador; el protagonista pertenece a un tiempo que ya no le corresponde al autor. Se sueña a sí mismo. El que sueña y el sońado son la misma persona, pero diferentes; son ajenos, distantes, otros; irreconocibles si se miran mutuamente. Esa distinción se indica por el desarrollo interior del personaje. Entre los puntos extremos de ambas personas ocurre el proceso de formación del cual me ocuparé.

La escritura va desocultando el sueño a medida que avanza el tiempo ficcional. La auto-observación se manifiesta a través de la mirada de sí por la evocación y la invocación. Son dos recursos necesarios para traer a la memoria el pasado que, quizá, se había olvidado y para hacer presente mediante la palabra el vacío ocupado por la ausencia de un objeto, sentimiento o recuerdo. Elizondo, en "Invocación y evocación de la infancia" de Cuaderno de escritura (2000: 16-39), analiza ambos elementos en la obra de dos autores, Proust y Joyce, que han hecho de la infancia el punto de partida. A diferencia de ellos, Elsinore es la manifestación de tales efectos a partir de la adolescencia, cuando Elizondo tenía 15 años.

Para Elizondo la evocación es un tipo de memoria que reconstruye momentos, recrea a través de vivencias y recuerdo de sensaciones. El periodo de este proceso corresponde a los tres años en los que estuvo recluido en la escuela militar, los cuales están registrados en su biografía. Es la yuxtaposición de pasado y presente en la re-experiencia de sensaciones precisas. Esa rememoración es imperfecta e incompleta, pues su deficiencia consiste en la insuficiente totalidad para recobrar plenamente la vivencia. La inconsistencia no es espacial, sino temporal, ya que supone olvidar y creer que lo vivido, en un pasado hipotético, corresponde al recuerdo de esa vida, de tal suerte que "la invocación, ya que ésta consiste, en cierto modo, en hacer presente algo que, como el futuro, de hecho está desprovisto de referencias sensoriales" (Elizondo, 2000: 21). 
En buena medida la multiplicación de mundos paralelos son efectos de la evocación y la invocación en la obra de Elizondo. ${ }^{2}$ En el caso particular de Elsinore, evocación e invocación no son la manifestación de mundos paralelos, sino devienen por la confusión provocada de la forma de narración. Todo el relato es una evocación de un tiempo anterior que no corresponde al presente, y es una invocación de la vida en la escuela militar. El libro en cuestión es una escritura que relee sus hechos, sus acontecimientos ficcionales, otro tiempo en una lectura del pasado desde el presente. Las descripciones y oraciones en Elsinore anhelan hacer presentes las sensaciones y reconstruirlas en una escritura que es reescrita.

Escribir un libro es, en cierta forma, releerlo. El texto se va construyendo de su propia lectura reiterada [...] La composición es simplemente la confusión de las palabras y los hechos; la confusión de estas cosas en el tiempo y en el espacio; la confusión que es su propia identidad [...] Es preciso, entonces conocer la identidad de esa confusión que persiste aún más allá de la certidumbre que la anima, y conocer, también, el orden en que, en el sueño de otro - del personaje que en su libro me está escribiendo que yo lo escribo a él- estamos inscritos o nos contiene correlativamente descritos por el otro, él o yo. Si de pronto una súbita revelación me hiciera saberme como el personaje del otro, y que ese otro pudiera ser real, el verdadero Salvador Elizondo de quien yo no soy sino el pseudo-Salvador-Elizondo y que siendo eso pretendiera escribir un libro en el que concibo a otro, al otro que puede ser el personaje de la novela cósmica que un dios está escribiendo. (Elizondo, 1994: 37)

Tal confusión es Elsinore. Dibuja una geografía del infinito en intersección con el instante. Elizondo rompe con una escritura

2 Sobre la manera en que la evocación y la invocación adquieren diversas formas en la obra de Elizondo, consúltese García-Galiano (2006: 11-20). 
solipsista en la medida en que no todo lo que surge y se da en la escritura son hechos de la mente del narrador, ya que ocurren otros hechos y anécdotas que son propias de la experiencia con otras personas y el mundo. La dimensión textual es la vida de un pasado hecho presente, manifestado por un sueño escrito, por ello, la falta de solipsismo en la escritura rompe con el "yo" del relato. En el espacio textual existe el lugar del discurso y el de la historia. El del discurso, como se verá, implica la formación y desarrollo de Sal; el espacio de la historia lleva en sí el aspecto simbólico de las tres dagas, como parte elemental del proceso de formación del protagonista.

\section{Elementos de formación}

Bildung $^{3}$ designa la formación corporal y espiritual. Implica, por otra parte, el proceso de desarrollo del individuo con relación a su entorno y con el resto de personas con las que se desenvuelve en los ámbitos sociales y culturales. Sí, sin duda existe el proceso de formación en diversos planos. Ello se da en doble sentido: simbólico y cultural. Aunque Fred presenta, igualmente, el desarrollo de formación, e incluso, dicho fenómeno es recíproco entre Fred y Sal. Expresión de ello es la búsqueda y hallazgo cuando escapan de la escuela militar, y también mediante la evocación del autornarrador desde la escritura como expresión de la memoria.

El espacio narrativo tiende a crear una ilusión de realidad, pues, genera tres fenómenos de puesta en discurso del texto: actorialización, temporalización y especialización. Interesa el segundo elemento, porque "la temporalización da cuenta de la cantidad y calidad de la sucesión de los estados y transformaciones que los sujetos de la narración sufren" (Cuevas, 2006: 41). Tales cambios

${ }^{3}$ Para un conocimiento más profundo y amplio, consúltese Salmeron (2002: $15-62)$. 
se expresan en relación con el mundo, el fuero interno, y expresan la individualidad e interioridad del protagonista en la formación de identidad. Ahora bien, la novela de formación está constituida por la imagen del personaje en desarrollo.

Algunas de estas novelas tienen un carácter esencialmente biográfico o autobiográfico, y otras no lo tienen; en unas, el principio organizador es la idea puramente pedagógica acerca de la formación de un hombre, y otras no la contienen en absoluto; unas se estructuran por el orden cronológico del desarrollo y educación del protagonista y carecen casi de argumento y otras, por el contrario, poseen un complicado argumento lleno de aventuras; las diferencias que tienen que ver con la relación que existe entre estas novelas y el realismo y, particularmente, con el tiempo histórico real, son aún más considerables. (Bajtín: 2003, 211)

El caso Elsinore es complejo a causa de su estructura argumentativa, porque no existe un hombre preestablecido que se desarrolla en la narración. Sal ya está formado cuando inicia el relato. Su sueño se revela con la escritura de tal suerte que, el tiempo de ésta no corresponde, simultáneamente, con el tiempo de la imagen del hombre en proceso de formación. Aunque Sal y Salvador son el mismo hombre, su distinción radica en el aspecto alcanzado por Salvador, autor de Elsinore, a saber, el cambio interno con relación al mundo y la identidad que ello implica.

La escritura pone de relieve la subjetividad mediante la descripción, cuya finalidad es reconstruir la memoria y el tiempo porosos, inestables e imperceptibles; permite descubrir, paulatinamente, el rostro de los demás, el mundo caduco y la propia personalidad del pasado. Quien escribe, Elizondo, entra en proceso de iniciación cuando su escritura evoca un pasado perdido y se descubre a sí

\footnotetext{
${ }^{4}$ Las cursivas son mías.
} 
mismo de otra manera. Antes se mencionó la importancia de la evocación y resulta oportuno recordar su concepto e importancia para resolver el rito de iniciación, así como comprender las relaciones manifiestas con Fred y Mrs. Simpson.

La fragmentariedad de la escritura consiste en su atemporalidad, pues la diégesis deviene pasado, presente y futuro. Dicha ambigüedad en parte se debe a que los hechos de los tres tiempos aparecen combinados; la confrontación entre el pretérito y lo que será compone la reflexión de ese desorden. En principio, estos elementos integran, poco a poco, la imagen de Sal; no obstante, hay otros componentes - las aventuras después de escapar de la escuela-, sobre todo, uno que parece importante, indispensable para el proceso de formación: el aprendizaje de la lengua inglesa. Puede notarse que la cualidad del relato se encuentra en su estilo bilingüe. La manera de combinar dos lenguas en los diálogos refleja que así es como hablan sus personajes y habitantes en donde ocurre la historia. La yuxtaposición de dos idiomas implica la relación de dos modos de pensamiento, costumbres, estilos de vida; además, el aprendizaje individual, aunque no sea pedagógico, es la característica de la novela de formación. Sal conoce y se expresa en inglés a las seis semanas de estar en Elsinore. "Seguí el precepto de Gracián. Hablé primero con los vivos y durante las primeras seis semanas de mi estancia allí, aprendí el idioma y hasta ahora el inglés ha sido mi segunda lengua" (Elizondo, 2001: 25).

En efecto, a partir del segundo apartado impera más el inglés, y para quien desconoce la lengua, es imposible la comprensión de la trama y los temas desenvueltos dentro y fuera de la escuela. Parte importante del proceso de formación es la función simbólica de las tres dagas, que aparecen en la narración. Son de la misma hechura, pues, son de la SS, pero distintas, porque son parte de una semántica ajena y pertenecen a personas diferentes. Las dagas son fundamentales para el tratamiento de la imagen del protagonista. 
La primera de ellas, en el apartado I, está en la casa de su tía. "Junto a la ventana había un escritorio; sobre una cubierta de terciopelo azul había un portarretratos con la fotografía de mi primo en uniforme, sus medallas y trofeos, insignias alemanas, una daga de los ss" (Elizondo, 2001: 14). Esta primera daga significa nostalgia, pérdida, ausencia del ser querido, muerto en la guerra.

La segunda de ellas aparece en el apartado II. "A ver, compita, le dijo Diosdado al Yuca tendiéndole una daga ss con el mango de cabeza de águila, como la que estaba en la mesa de mi primo, ráscale [la etiqueta de la botella de whisky] tantito para ver si es cierto. El Yuca la rechazó y sacando [...] una faca mexicana, curvada y afilada [...] Aquí traigo la mía, dijo, y empezó a escarbar" (Elizondo, 2001: 41). Esta daga simboliza la muerte, pues con ella Diosdado mata al Yuca, después de una borrachera, con el whisky que Sal les había obsequiado el Día de Gracias.

Finalmente, la tercera está en los apartados IV y V, y es ésta la que Sal adquiere. "En un empeño compré una daga del ss con mango en forma de águila como la que estaba en el escritorio de mi primo" (Elizondo, 2001: 69). Ella significa, en el contexto y semántica de la historia, autoreconocimiento de Sal, el protagonista, a través de Salvador, el autor. Al final y como parte del remate de Elsinore, se realiza un sorteo para dar regalos sorpresa y la papeleta que toma Sal es la de su nombre; de esa manera se regala a sí mismo la daga. Representa la identidad del protagonista, autorreconocimiento.

Puede notarse que la escritura sirve para pensarse a sí, es la prueba de que Elizondo fue otro y ahora es alguien distinto. Sin la escritura todo podría ser ilusorio, una mentira. Pese a ello, como todo relato tiene su final, la historia de soñar escribir también se agota. El campo semántico de la escritura es la memoria, la inspiración, la tinta, el cuaderno, el propio sueño que es el móvil de la escritura. 


\section{Cuaderno}

Su aspecto mayor es la relación de significado entre el título de la obra y la forma de trabajar de Elizondo. Una respuesta dada a una entrevista aclara más el tema. Adolfo Castañon indaga sobre uno de los personajes principales de la obra de Elizondo, el escritorio, “qué es ese lugar de trabajo?”, pregunta. El autor responde:

Yo me lo pregunto mucho [...] y no tengo un lugar preciso para escribir [...] Yo escribo a mano. Siempre escribo en cuadernos, nunca en hojas sueltas, porque me gusta tener a la vista y a la mano absolutamente todo lo que he escrito, porque me pasa muchas veces que me cuesta muchísimo trabajo escribir una cosa y la deshecho donde va, y luego, dos o tres semanas después la veo por necesidad al hojear el cuaderno y encuentro que no está mal y que puede mejorarse y entonces la vuelvo a coger, ese es el sistema. (Castañón, 2006: 65)

Por tanto, trabajo e inquietud estética se reflejan en la síntesis de Elsinore: un cuaderno. La relación cuaderno, escritura, memoria y sueño se condensan en una idea total en la mayoría de las obras de Elizondo; sin embargo, en el caso particular, existe un elemento adicional, a saber, la evocación, pues se mezcla con la escritura, la memoria y el sueño; por tanto, ¿cuál es su diferencia con respecto a la memoria? La destrucción fenomenológica del tiempo hace de la memoria escritura. La memoria, además de ser una facultad, se vuelve un recurso literario indispensable para el manejo del tiempo; es un elemento mediante el cual el narrador logra la evocación. La evocación es la recuperación de esa ausencia. El sueño es la presencia que, finalmente, terminará por agotarse. La cosa que se reflexiona se vuelve real, y en ese proceso algo se pierde. No son personajes lo que se narra, son evocaciones de una memoria - en la escritura- que trata una ficción, en parte, real, que identifi- 
ca situaciones, hechos, personas, sentimientos, en parte ficciones, confundiéndose entre sí, y, por tanto, indistinguibles. La realidad no se borra, apenas se distingue.

Estoy sońando que escribo este relato. Las imágenes se suceden y giran a mi alrededor en un torbellino vertiginoso. Me veo escribiendo en el cuaderno como si estuviera encerrado en un paréntesis dentro del sueño, en el centro inmóvil de un vórtice de figuras que me son a la vez familiares y desconocidas, que emergen de la niebla, se manifiestan un instante, circulan, hablan, gesticulan, luego se quedan quietas como fotografías, antes de perderse en el abismo de la noche, abrumadas por la avalancha del olvido y sumirse en la quietud inquietante de las aguas del lago. Las palabras que escucho mientras sueńo que escribo parecen venir de un más allá, desde una vigilia remota en el tiempo y en el espacio, y aunque las oigo con claridad no las entiendo, como si estuvieran dichas en una lengua vestigial o ya olvidada. Todo está inscrito en la brumosa lejanía del olvido y los seres y las cosas aparecen envueltos en esa lentitud de lo que apenas empieza a ser recordado, de lo que acaba de despertar a la vida renovada de la memoria. Sobre la página del cuaderno en que escribo el sueño proyecta, difusas e imprecisas, las imágenes que guardan todavía el topor y la laxitud de su propio sueño de olvido. (Elziondo, 2001: 9-10)5

La escritura estimula la memoria y el recuerdo. Sus diferencias son cualitativas. El cuaderno es el espacio de trabajo, un método y sistema estéticos donde se práctica la escritura; sirve como el lugar de la historia. Sólo en el libro, sueño y escritura son lo mismo, comparten una sola naturaleza ontológica; son recíprocos cuando uno alude al otro en el proceso de evocación; la memoria al surgir se vuelve escritura, el recuerdo se refleja en las palabras.

${ }^{5}$ Las cursivas son mías. 


\section{Teoría de espejos}

El espacio de Elsinore: un cuaderno es memoria que también es escritura, lo cual produce un reflejo, a lo que denomino "teoría de espejos", pues el cuaderno de trabajo donde escribe, corrige, borra y vuelve a escribir es, al mismo tiempo, la memoria y el sueño; simultáneamente, la escritura es el contenido de la realidad interior sobre la cual trabaja el autor: el desdoblamiento del personaje como narrador y éste como personaje. Ello es manifiesto en el apartado III del relato, en donde el sueño del protagonista, Sal, está dentro del sueño del narrador, Salvador Elizondo, o sea, el propio relato. Los mundos paralelos del sueńo corresponden a los de la escritura. En esto persiste una vaga diferencia entre el personaje ficcionalizado y el narrador empírico. Dicha ambigüedad es una falsa identidad, que radica en la confusión entre la narración real y la narración ficcional de la vida que cuenta Elizondo. Paul Ricoeur denomina a esto refiguración. El concepto identidad narrativa esclarece este aspecto de identidad, importante para responder: ¿quién es el autor de la acción en la narración?

La identidad narrativa es la unión de la historia y la ficción. Dicha unión es manifiesta por el proceso cruzado de la ficcionalización de la historia y la historicización de la ficción. Ricoeur atribuye a esta dialéctica el tercer tiempo que no puede ser asignada ni a la historia ni al relato de ficción; se asigna al individuo "o a una comunidad de una identidad específica que podemos llamar su identidad narrativa" (2009: 997). El primer contraste para llegar a este concepto ha sido entre un tiempo histórico y un tiempo de la ficción, es decir, el tiempo de vida y el tiempo de la historia narrada; en segunda instancia, el paralelismo "del pasado histórico y los efectos de sentido producidos por la confrontación entre el mundo del texto y el mundo del lector" (997). 
Ricoeur sugiere que su respuesta, al conocer el nombre propio del autor, es narrativa. "La historia narrada dice el quién de la acción" (2009: 997). La persona que sea quien hace la acción, encuentra su identidad en sí mismo y en la narración. La identidad de Elizondo deja de ser dilema cuando su análisis descansa sobre el tercer tiempo, refiguración, a saber, la identidad narrativa, que hace posible el cambio, la mutabilidad de sí mismo siendo otro a través del lector; la historia y la ficción sobre sí registran el proceso de formación del personaje. Elizondo cuenta una historia a sí mismo sobre sí, misma que es sońada; y ese sueño es la escritura que se manifiesta mediante la memoria. El tiempo fenomenológico nos da cuenta de la diferencias entre el Elizondo de la escuela militar Elsinore y el Elizondo de la novela Elsinore. Cuando el lector descubre ese proceso encuentra, al mismo tiempo, la identidad narrativa. Los cambios, además de los temporales y espaciales, ocurren en el desarrollo de formación del narrador-personaje.

El epígrafe que inicia el relato corresponde a Ernst Jünger y plantea cierta solución. Esa cita propone a la melancolía provocada por el recuerdo de días gratos, sus efectos y el dolor que causan por ser inasibles. El reflejo de tales memorias son las palabras, orales o escritas, cuando se cuenta la historia de esos días pasados. Hasta ahora ello ha sido una constante en el argumento. Se piensa en el pasado mientras se piensa la escritura, lo cual hace auténtico al sujeto de la narración. Sal es pensado por Salvador.

Todos vosotros conocéis la profunda melancolía que nos sobrecoge al recordar los tiempos felices. Esos tiempos que se han alejado para no volver más y de los cuales estamos más implacablemente separados que por cualquier distancia. Y las imágenes de la vida son más seductoras todavía vistas en el reflejo que nos dejan, y pensamos en ellas como en el cuerpo de una amada difunta que 
reposara bajo tierra y que de pronto se nos apareciera, como un luminoso espejismo (Ernst Jünger citado en Elizondo, 2001). ${ }^{6}$

Esta cita indica un tiempo inasible que el recuerdo recupera mediante la conciencia y lo hace vivo otra vez cuando la evocación se desdobla en el espacio, es decir, en el cuaderno. La memoria y el recuerdo dan orden a la discontinuidad de la experiencia hallada en el pasado. El proceso de escritura se vuelve vital, porque salva lo que ya no pertenece al tiempo, lo que es indeterminado. De la misma manera, escribir recrea el tiempo. Elsinore: un cuaderno es sueño y búsqueda, pero también deseo por recuperar ese olvido y encontrarlo. El sueño lo revela, también la escritura. La escritura es un deseo del autor-protagonista por realizar los hechos olvidados. Las palabras reducen las distancias entre el pasado y el presente, suprimen lo temporal de los recuerdos, haciéndolos reales, más próximos, menos lejanos y lentos. Esa es la confusión. El sueño es la escritura.

Otro factor que aporta a lo vacilante de la diferencia entre lo sońado y lo escrito oscila en que las dos vidas, Sal y Elizondo, se inscriben, coinciden en algún momento. Los dos personajes se hacen a sí mismos y mutuamente se realizan. En otra entrevista, Margarita García Flores le pide a Elizondo aclarar por qué la creación literaria es la aspiración irrefrenable de sueño. "Entiendo por escritura [explica Elizondo] la totalidad de las posibilidades que esa técnica propone para concretar los hechos lingüísticos; todos los hechos concretables o cuya realidad es representable mediante la escritura" (1974: 289).

La propuesta alcanza la coincidencia del autor con el ser imaginado o recordado. "Coincidir con el ser imaginado, configurarlo mediante la escritura en el horizonte para alzarse hasta él y estabilizarse estabilizándolo, implica una victoria sobre el tiempo" (Ló-

${ }^{6}$ Las cursivas son mías. 
pez, 2010: 325). La escritura, el cuaderno, la memoria funcionan como el espejo que refleja la imagen del protagonista en proceso de formación; la palabra escrita multiplica las diversas imágenes que va adquiriendo el autor a lo largo del tiempo, desde el año 1947 hasta 1987, año que indica el final del libro. De ahí la necesidad de escribir, porque de lo contrario se disocia y desaparece el autorpersonaje, el ambiente en el cual Sal vivió, las sensaciones con las demás personas y, lo más importante de todo, su propia imagen de esos años.

\section{Montaje}

El concepto de montaje proviene del cine, aunque Elizondo aclara su significado y procedencia; no obstante, es oportuno anotar las descripciones del arte cinematográfico y después citar la definición dada por el autor. Eduardo A. Russo (1998) explica que el montaje es una selección de elemento y material que definen qué imágenes emplear para armar la película; sirve para combinar planos; marca el tiempo de duración de las escenas y de objetos mostrados. En el diccionario de este autor también se definen y diferencian el montaje acelerado, montaje americano, montaje de choque, montaje en el plano, montaje narrativo, montaje paralelo y montaje ritmico.

Para Elizondo el "montaje es el sistema en el que se fundan los ideogramas chinos, es la conjunción de dos ideas concretas que forman una tercera idea abstracta en la mente, o de dos elementos concretos, o dos imágenes, o dos situaciones, digamos, que chocan" (Berenzon, 1996: 24).

Ahora bien, si se piensa en las dos lenguas con las que la estructura y diálogos del relato están constituidos, entonces los idiomas inglés y español son grandes imágenes o ideas que se yuxtaponen, construyendo otra distinta. Elsinore es un signo, cuyos caracteres particulares y compuestos muestran, por una parte, su significado 
mental que corresponde al pasado que se evoca y, por otra, designan el presente de la escritura. Ese signo es un ideograma que pone en escena la presencia de un pasado reconstruido.

La novela funciona como un ideograma chino, collage integrado por ambas lenguas; el sueño total que es Elsinore se va descifrando y construyendo a medida que cada carácter se incorpora para organizar y terminar la estructura del relato. La yuxtaposición de dos idiomas no es el único montaje presente, también existe el montaje paralelo, el cual está organizado por dos acciones simultáneas desarrolladas en el relato y que ocurren en espacios diferentes, unidas de modo dramático. Estas corresponden al momento preciso en que Sal y Fred escapan en el bote Jenny, mientras Yuca es asesinado por Diosdado con la navaja de la SS.

\section{Conclusiones}

Elsinore: un cuaderno es el relato que tiene por historia el acto de narrar, se noveliza la escritura. Lo imaginario es incorporado a lo que fue, al pasado, sin quitarle su perspectiva realista. El tiempo es en la narración algo recuperado, se vive en ella porque su manifestación es la escritura misma que presenta los bellos días, los felices momentos. Está concluida la imagen del hombre que fue Elizondo, su proceso de formación se efectúo por la escritura. "El tiempo narrado es como un puente tendido sobre el abismo que la especulación abre continuamente entre el tiempo fenomenológico y el tiempo cosmológico" (Ricoeur, 2009: 994). El tiempo fenomenológico es el de una conciencia individual, personal, encontrado en el cuaderno de trabajo; el tiempo cosmológico es el tiempo de los días y las noches, el que rige a las sociedades con su calendario y fechas marcadas, es el tiempo de la ciencia y la cultura. En ambos tiempos la figura de Sal y Salvador se realizan. "La invención del mundo que el artista hace es sólo de lenguaje” (Cuevas, 2006: 69); 
sin embargo, ese mundo sí existió, pero no se ha olvidado en su totalidad, aspectos de ese mundo descubierto surgen del sueño a la escritura.

El personaje y su autor están ante la reflexión de su pasado y una realidad que les correspondía. No hay una reflexión sobre la propia escritura, pero sí es un discurso autorreferencial, metadiscurso, metatextual. Dado lo anterior, la composición de Elsinore parece todavía extraña, porque la posición del autor nunca es la del personaje principal, aunque es autobiográfico; también reconozco que Sal y Salvador se complementan y pertenecen a tiempos diferentes y que uno le ayuda a formarse al otro. Sin embargo, aunque ello sea así, la escritura me aclara ciertos aspectos, como por ejemplo: la escritura escribe el sueño y la memoria. La escritura habla y narra un pasado desde la posición del autor, pero también desde la postura del protagonista. La historia se observa por la escritura, por la mirada de Elizondo, autor. "El papel mediador de lo imaginario se acrecienta, en efecto, cuando pasamos del tema de la reinscripción del tiempo vivido en el tiempo cósmico al de la dimensión pasada del pasado" (Ricoeur, 2009: 907). La narración de un pasado adquiere sus dimensiones cuando la escritura designa el sueño. Para la voz narrativa del relato el sueño es un presente, un instante, aunque los hechos que se marcan y acontecen ya son pasado.

Además de mostrar el desarrollo de formación se muestran algunos contenidos temáticos que justifican dicho proceso, así como notar de qué modo ocurre tal proceso; independiente de ello, se expone cómo técnicas — el montaje- de otras áreas se incorporan al relato. No parece simple el bilingüismo, aunque el país donde se desarrolla el evento de la historia lo exigiría, no era necesario llevarlo a cabo. 


\section{Bibliografía}

Bajtín, Mijaíl M., 2003, Estética de la creación verbal, México, Siglo XXI.

Barthes, Roland, 2009, El grado cero de la escritura, México, Gandhi.

Beristáin, Helena, 2010, Diccionario de retórica y poética, México, Porrúa.

Berenzon, Boris, 1996, "Entrevista a Salvador Elizondo", Filosofía y Letras. Boletín, núm. 9, mayo-junio, pp. 21-27.

Castañón, Adolfo, 1995, "Las ficciones de Salvador Elizondo", en Arbitrario de la literatura mexicana, t. I, México, Vuelta.

, 2006, "Entrevista con Salvador Elizondo. Los secretos de la escritura", Revista de la Universidad de México, núm. 26, pp. 58-66.

, 2007, "Salvador Elizondo. Idea del hombre que se hizo prosa", Revista de la Universidad de México, núm. 36, pp. 79-88.

Cuevas Velasco, Norma Angélica, 2006, El espacio poético en la narrativa. De los aportes de Maurice Blanchot a la teoría literaria $y$ de algunas afinidades con la escritura de Salvador Elizondo, México, Universidad Autónoma Metropolitana.

Curley, Dermot F., 2008, En la isla desierta. Una lectura de la obra de Salvador Elizondo, México, Universidad Autónoma Metropolitana / Aldus.

Derrida, Jacques, 1986, La escritura y la diferencia, Barcelona, Anthropos.

Durán, Manuel, 1973, "Salvador Elizondo", en Tríptico Mexicano. Juan Rulfo, Carlos Fuentes, Salvador Elizondo, México, Secretaría de Educación Pública.

Elizondo, Salvador, 1972, El grafógrafo, México, Joaquín Mortiz. 
,2000, Cuaderno de escritura, México, FCE.

, 2001, Elsinore: un cuaderno, México, FCE.

García Flores, Margarita, 1974, "Salvador Elizondo", en Cartas marcadas, México, UNAM, pp. 289-300.

García-Galeano, Javier, 2006, "Prólogo. El principio de la invocación”, en Salvador Elizondo, Elsinore. Un cuaderno, México, Asociación Nacional del Libro, pp. 11-20.

Lavista, Paulina, 2008, "El mamometro" (selección de distintas entradas de los cuadernos de Elizondo), Letras Libres, año X, núm. 115, julio, pp. 47-52.

Lizalde, Eduardo, 1999, "Salvador Elizondo", en Tablero de divagaciones, t. I, México, FCE, pp. 337-338.

, 1999, "Otro apunte sobre Salvador Elizondo", en Tablero de divagaciones, t. I, México, FCE, pp. 339-341.

López, Amadeo, 2010, "El universo novelesco de Salvador Elizondo", en Rafael Olea Franco (ed.) y Laura Angélica de la Torre (colaboradora), Doscientos años de narrativa mexicana, siglo XX, vol. 2, México, El Colegio de México, pp. 321-344.

Paz, Octavio, 1985, "Máscara. Recuerdos del teatro en un tiempo de crisis", Vuelta, vol. 9, núm. 100, marzo, pp. 6-10.

Peñaloza, Joaquín Antonio, 1977, "Salvador Elizondo", en Cien mexicanos y Dios, México, Jus.

Ricoeur, Paul, 1986, Tiempo y narración, vol. I, México, Siglo XXI. , 2009, Tiempo y narración, vol. III, México, Siglo XXI.

Russo, Eduardo A., 2001, Diccionario de cine. Estética, critica, técnica, historia, Buenos Aires, Paidós.

Sada, Daniel, 2009, "La escritura obsesiva de Salvador Elizondo", Revista de la Universidad de México, núm. 66, agosto, en: http:// www.revistadelauniversidad.unam.mx/6609/sada/66sada.html. 
Salmerón, Miguel, 2002, La novela de formación y la peripecia, Madrid, Literatura y Debate Crítico.

Vicens, Josefina, 2010, El libro vacío, México, FCE.

Yébenes, Zenia, 2008, Breve introducción al pensamiento de Derrida, México, Universidad Autónoma Metropolitana. 